Article

\title{
Environmental Legislation in European and International Contexts: Legal Practices and Social Planning toward the Circular Economy
}

\author{
Grigorios L. Kyriakopoulos (D)
}

Photometry Laboratory, Electric Power Division, School of Electrical and Computer Engineering, National Technical University of Athens, 15780 Athens, Greece; gregkyr@chemeng.ntua.gr

\begin{abstract}
Environmental issues and relevant policy plans are steadily involving the circular economy (CE) concept into business development. Such significant approaches to achieve environmentally sustainable economic development, they are supported and reinforced by dissatisfaction with the linear traditional approach of "take-make-dispose" model. This traditional production model is bounded on large quantities of directly accessible resources and energy. Therefore, at this study the transition of the linear take-make-dispose model was investigated toward the circularity approach of cost-effectiveness over eco-efficiency. In this respect the study focused on, mainly European, environmental legislation at the industrial sector and the abiding legal practices and social planning regarding CE. The collective presentation of directives and regulations was accompanied by representing those research considerations, social reflections, and legal practices' impacting. The challenging issues and the key developmental prospects for future researches have been conclusively denoted.
\end{abstract}

Keywords: environmental legislation; circular economy; social planning; European Union Directives; regulations; social planning; public law; private law

Citation: Kyriakopoulos, Grigorios L. 2021. Environmental Legislation in European and International Contexts: Legal Practices and Social Planning toward the Circular Economy. Laws 10: 3. https://doi.org/10.3390/ laws10010003

Received: 11 December 2020 Accepted: 12 January 2021 Published: 14 January 2021

Publisher's Note: MDPI stays neutral with regard to jurisdictional clai$\mathrm{ms}$ in published maps and institutional affiliations.

Copyright: (C) 2021 by the author. Licensee MDPI, Basel, Switzerland. This article is an open access article distributed under the terms and conditions of the Creative Commons Attribution (CC BY) license (https:// creativecommons.org/licenses/by/ $4.0 /)$.

\section{Introduction}

Nowadays plentiful researches have systematically approached legislation issues regarding manufacturing and industrial conditions of production. Such issues include incidents of fatalities and injuries in the industry, equipment in the workplace, personal protection, lifting systems, pressure systems, safety signs and electricity, transportation of chemicals through supply chains, first aid, as well as health protection and prevention of occupational diseases among workers at processing and recycling waste materials (Dodd 2002; Ilyassova et al. 2020).

Among legislation production of procedural interest is that of occupational health and safety (hereinafter H\&S) legislation, relative to the construction industry. Such an occupational H\&S legislation has been highly significant and especially appreciated among developing countries, since it must meet the current realities in the construction industry, being enforced at the local level, and enabling central governments to address corruption (Adeyemo and Smallwood 2017; Adeyemo and Smallwood 2019). It is noteworthy that the relevant legislation system does not always positively influence H\&S performance in the construction industry, thus, severely affecting the implementation of $\mathrm{H} \& \mathrm{~S}$ legislation and badly impacting on overall projects' performance (Adeyemo and Smallwood 2017; Adeyemo and Smallwood 2019). At a typical H\&S legislation governing the UK industrial sector can be extended from the control of hazardous substances up to health and safety conditions about noise, handling operations, displaying screen factors, and precautionary risks of fire and explosion (Dodd 2002).

In a similar research it was investigated the effect of occupational safety and health (hereinafter $\mathrm{OSH}$ ) legislation in reducing workplace accidents at Spanish manufacturing 
throughout the period 1988-2004 (Arocena and Nunez 2009). It is critical to estimate the relationship between the number of serious injuries and the potential risk factors, by means of diverse specifications of the negative binomial regression model for panel data. Interestingly, the adoption of the new OSH regulation contributed to the reduction in injuries cases within advanced manufacturing sectors, but the accident rates in traditional manufacturing did not show any statistically significant change following such a legislative reform (Arocena and Nunez 2009).

Another critical consideration is the examination of those distinct features between private and public law, in order to determine those traditional private law regimes that may provide a sound basis to improve the law's capacity to cover the circular economy (hereinafter CE) principles (preferably) in a proactive manner. Such an anatomy on the distinction between public and private law is currently blurred, thus, necessitating legal techniques that aim to regulate the relationship among private parties. It is not surprising that most of these legal techniques are also utilized in the domain of public law, which governs relationships between private parties and central governments (Ballardini et al. 2021).

In this section the theoretical focus on the H\&S and OHS legislation was selected in order to represent the legislative affection of industrial and manufacturing sectors and processes to the built environment and the human capital, while the environmental protection and wastes management are certainly fields of future legislative interest. At the following sections the research has focused on the environmental legislation in the industrial sector, as well as on describing the conditions of public and private law to foster the CE. Then, an integrated discussion on the key-findings was developed, while the concluding remarks have succinctly denoted the key-issues and the future research prospects and challenges offered.

\section{Environmental Legislation in the Industrial Sector}

The environmental legislation in the industrial sector is a challenging topic because of the ongoing advancements of production processes and the consumerism patterns. The critical points of consideration are the transitions from local transactional economies toward international and open markets, the new technological modes of products launching and promotion through social media influencers and e-commerce, as well as the adoption of circularity over linearity in products and services of developing and developed economies. Therefore, legislation has to be also evolved in order to support these transactional socioeconomic phenomena, while special provision should be taken for all these economic activities to abide to the common legislation rules, regulations, and policy regimes.

This section consists of two subsections referring the specific paradigms/cases from the EU context, as well as the cost-effectiveness and eco-efficiency targets of linear and circular economy. The main shortcomings of the traditional linear approach over $\mathrm{CE}$, are that the linear economy is related to the direct disposal of used products, thus pressing directly the manufacturing and industrial units to produce ever more to meet the highconsumerism and indirectly causing excessive depletion of natural sources, either for raw materials mining, or environmental degradation caused by the whole life cycle process of products: materials mining, production, distribution (supply chain and logistics management), consumption, decommissioning. On the other hand, the $\mathrm{CE}$ is approaching used products of useful raw material for a second, or more, rounds of utility, thus, adding value to those depreciated products. The prevention of products' direct disposal is also supporting lesser levels of pollutants emissions from industrial units, as well as saving of raw materials' deposits. Consequently, it is of utmost importance the legislative adaptation to those socio-economic transitions and an integrated analysis of these issues has been approached at this study.

\subsection{Environmental Issues of Legislative Interest in the Industrial Sector}

Industries are certainly generating pollutant emissions in water source, ground, and air that face current environmental regulations at both European Union (hereinafter EU) and 
international contexts (Macovescu and Guta 2012). It is indicatively noted that endocrinedisrupting effluents from the textile industry were considered in the past as contentious waste and hence it was not covered in systematic depth, but it followed compliance methods and requirements related to general manufacturing industry (Simpson et al. 2000). The relevant literature covers many diverse practices and geographical dispersion of environmental legislation: from the offshore oil industry in China (Lu and Xia 2004) and the textile-manufacturing industry in the UK (Cooper 1992; Simpson et al. 2000), up to environmental legislation regarding the steel industry in the U.S. (Hogan 1995). Therefore, the handling and coordination of such a broad legislative production could be feasibly supported by setting-up a database, which has been recommended toward the easier control and harmonization of diversified environmental regulations followed by experts in the contexts of EU and international legislation, accordingly (Macovescu and Guta 2012). However, it has been reported a gap in consumer protection that is caused by the absence of a general EU regulatory framework for services. Such a constraint can be partially overcome through standardization (Mak and Terryn 2020).

Among today's environmental issues that are generating high legislative interest are wastes generation and disposal. Waste generation is considered as a key by-product of modern economic and social living and consumption behavior and one of the constantly worsening problems for environment, human health, and EU economy, since it is estimated that materials sent to landfill in the EU could have a commercial value of around $€ 5.25$ billion per annum, which is directly related to economic loss (Pouikli 2020). Excessive economic costs of infrastructure are also incurred for the collection, sorting, and management of waste, as well as for confronting the resource crisis due to the over-exploitation of natural capital caused by population growth, urbanization, unsustainable economic endeavors, and consumption patterns (Pouikli 2020). In this context large-scale industrial units have been built regarding mining and processing of rare earth element (hereinafter REE). This industrial process generates significant quantities of waste, while the ores contain variable amounts of non-target toxic metals, fluorine, and radionuclides. The chronologically earlier processes of REE mining and processing have led to significant environmental impacts in several countries, causing research interest to be driven on finding and identifying several viable REE resources among the EU, while it is likely that one or more of these will be predominately exploited in the near future. Subsequently, EU environmental legislation should determine whether the EU's existing environmental and radiation protection legislation is adequate to support such a sustainable REE exploitation (Keith-Roach et al. 2015).

Another critical aspect necessitating the production of a variety of environmental legislation is the strengthening of global trade forces companies for them to comply with environmental regulations and subjected to continuous modifications. The second half of the 20th century has been characterized by a dramatic increase of environmental directives and regulations, while law enforcement agencies expanded their active analysis of companies and their products (Miehe et al. 2015). A plethora of companies have been, even, accused of selling non-compliant products by both enforcement authorities and competitors ever since. Therefore, companies and products compliance are greatly linked with their internal processes and their adaptability to manage changes (Miehe et al. 2015). Such management of change entails different business types related to size, number of employees, suppliers and materials, thus, the environmental legislation development has focused on those applicable processes ensuring compliance with regulations for various hazardous substances that can be successfully tested among highly industrialized companies of developed economies. In such a study over 70 companies of different industries in Germany were tested in the light of those essential steps and standardized approaches for material, substance, and risk assessment—mainly the following standards of: ISO 31000, 14040, 14044 and EN50581—being suitably determined and selectively applied (Miehe et al. 2015). 


\subsection{Cost-Effectiveness over Eco-Efficiency in Linear and Circular Economy}

The cost effectiveness over eco-efficiency is actually a contentious topic, having multiple impacting on almost all entrepreneurial activities of linear economy. However, two critical issues that have to be addressed are first, researchers to fully understand those critical aspects that ensure the application of eco-efficiency at the transition from linearity to circularity economic contexts and second, in what ways legislative regulations and directives could be extended to cover the new transaction routes entailing the CE compared to the well-established, but rigidly running, linear economy. In the upcoming years it is anticipated that technical advancements will go ahead legislative protection of them thus, at this study, it is noteworthy to represent typical cases of high environmental, social, and regulatory interest.

The agricultural sector and the agri-food industry are considered as prime sectors of determining optimal levels of eco-efficiency based on resource utility of social cost to consumers and financial benefits to farmers. Such a common resource, that is the excessive use of fertilizer, threatens sustainability and also causes negative externalities in the form of hidden social cost to the society (ul Haq et al. 2020). These authors estimated the social costs and benefits in alignment with excessive use of chemical fertilizers on crops and also evaluated the eco-efficiency of cultivations of local agrarian interest. Data analyses showed that the overuse of fertilizers at local cultivations could substantially reduce the per-hectare greenhouse gas emissions (hereinafter GHGs) by applying eco-efficient fertilizer target levels. Besides, the optimal level of fertilizers equals social costs to social benefits, showing that the farmers cannot only reduce their fertilizer quantities without compromising the crop yield, but can also contribute to the sustainable air environment of low GHGs levels. From a legislative point of view provision should be taken to micro-finance from banks or local large companies enabling farmers to replace the older methods of agricultural production with newer ones in order to achieve social and eco-efficient levels as well as to maintain viable yield levels (ul Haq et al. 2020).

Similarly, food production and transformation have increasing impact on the environment. Therefore, agri-food industry can improve its environmental performance by increasing the value of the processed products. In this respect it is noteworthy a new technological approach to evaluate eco-efficiency beyond the production costs, while accounting for the functional value of the foodstuff. In such a technological approach the conventional use of the monetary unit as the product value, authors proposed a value-based metrics that is closer to consumer interests, e.g., content of functional nutrients, taste and abatement of harmful substances (Chaudron et al. 2019). This technological approach evaluated the eco-efficiency of de-acidified cranberry juice by two alternative technologies in Quebec, Canada. Actually, the adoption of an approach closer to consumers' interests, enables eco-efficiency results to be more relevant for decision-making in the context of cleaner production, particularly when the monetary value is not reliable. Again the trading law can be also extended to protect producers and byers of such new routes of production and consumption.

Among the crucial sectors that support the economic growth of either developing or developed economies, are transportation and tourism sector. Since air and liquid emissions are related to economic activities of shipping and its contribution to the degradation of air quality, health, and built environment in port-cities, there is increasing attention to investigate the environmental cost by eco-efficiency performance indicators from vessel traffic, in general, and passenger sub-sectors, in particular, under diverse geographical and regulatory contexts. These research objectives are of paramount importance since sustained market growth and shipping - also deriving into pollution concentration and a steady increase over residents and visitors-necessitates the identification to internalize environmental impacts (Tovar and Tichavska 2019). Typical emission assessment involved the passenger port hubs of Las Palmas, St. Petersburg, Hong Kong over a twelve-month period where environmental cost was obtained from a top-down approach and the latest seaport-related cost patterns. Besides, eco-efficiency performance indicators were deter- 
mined by the ratio of product/service impacts (externality costs) and its added value (port profiles). Supporting international and regional policy design within the selected harbors and ports under similar traffic conditions implies strategic policies to enhance abatement actions toward shipping sectors and relevant legislative reforms at the shipping law: financing, construction, insurance, transportation of goods and people by sea (Tovar and Tichavska 2019).

Another paradigm of eco-efficiency in transportation sector is that of Philippot et al. (2019). These authors denoted that GHGs emissions and the battery cost of electric vehicles (EVs) have been well studied, but coherent boundaries between environmental and economic assessment are needed to investigate the eco-efficiency of batteries. In such a research, environmental analysis and economic assessment of the manufacturing of one specific lithium-ion battery chemistry were deployed taking into consideration the key-parameters of manufacturing place, production volume, commodity prices, and energy density. Authors reported that the battery cost-commodity price association was proven much lower than that of battery cost-production volume association. Moreover, life cycle assessment unveiled that the electricity mix was used to power the battery factory and it was proven as a key parameter for the impact of the battery manufacturing on climate change. In improving the battery manufacturing eco-efficiency, a high production capacity and an electricity mix with low carbon intensity are suggested. Furthermore, the optimization process was proposed by reducing the electricity consumption during the manufacturing. In this paradigm it is also important the legislative framework to jointly ensure the technical advancements of higher pack energy density, in alignment with the impact on climate change of the pack manufacturing in regulatory thresholds of $\left(\mathrm{kg} \mathrm{CO}_{2} \mathrm{eq} / \mathrm{kWh}\right)$.

In the context of transition from the linear to the circular economy two paradigms in which the circular economy was proven highly effective are: (a) health and hygiene sector and (b) decarbonization of industrial sector through renewables use in energy production. Regarding the first one of the paradigms above, the health and hygiene conditions are related to environmental implications, while using cloth instead of disposable products, utilizing bio-materials or enabling recycling and composting. Such paradigms are that of single use disposable face masks for the COVID19 pandemic as well as the disposable baby diapers (Mendoza et al. 2019). The evaluation of economic and environmental savings that could be achieved by eco-design and cleaner production of disposable baby diapers involves the use of an optimized absorbent core and innovative bonding technologies to replace gluing systems in diaper manufacturing. A cradle-to-grave life cycle costing proved that novel design and manufacturing of "glueless" diapers can reduce costs by $11 \%$ compared to similar conventional products, equaling to $€ 250$ million saving at the EU level. Besides, the eco-efficiency analysis unveiled that the glueless diapers were $7-170 \%$ more eco-efficient ( $€$ /impact) than the standard diapers in the light of the environmental impact considered (Mendoza et al. 2019).

Regarding the second paradigm, the decarbonization of the energy sector, it is related to a high number of technical options available for energy production and among them the hydrogen production was one of the most promising ones (Valente et al. 2019). Nevertheless, the suitability of these technical options necessitate a thorough evaluation from a life-cycle perspective. In this context, the standardized concept of eco-efficiency is suitable from a life-cycle perspective, entailing the environmental performance of a product system to its value (Valente et al. 2019). Benchmarking the eco-efficiency performance of renewable hydrogen produced through biomass gasification against conventional hydrogen from the steam reforming of natural gas involves the harmonized environmental indicators of global warming, acidification, and cumulative non-renewable energy demand. Additionally, the product system value was based on the levelized cost of hydrogen with and/or without internalization of the external socio-environmental costs associated with climate change and human health. Authors stated that by combining life-cycle environmental and economic indicators under the umbrella of the eco-efficiency assessment, it is disclosed that the renewable hydrogen option outperformed the conventional one, which was further 
remarked when implementing socio-environmental externalities. In this regard, a relative eco-efficiency performance can be estimated for the renewable hydrogen option when benchmarked against conventional hydrogen.

\section{Environmental Legislation in the Context of Circular Economy}

The legislation referring to environmental issues of economic interest is thriving. In such a systematic approach and organization of this literature production, the legislative framework was collected and organized into three general dimensions: policies, products, services. In the following section each one dimension has been further analyzed in alignment with the relevant key-aspects and specific issues of environmental priorities, mainly responding to European regulations and directives.

\subsection{Legislative Tools towards Circular Economy-The "Policies" Dimension}

EU has produced laws on the disposal of waste for over 30 years and laws concerning the environmental performance of products for over 20 years. However, this legislative production is not forming a cohesive whole, which is about to change (Hughes 2017). In this context the European Commission (EC, the body responsible for proposing new EU legislation) published its Circular Economy Package in December 2015 having the stated objective of "closing the loop" of lifecycles among products (Hughes 2017). The Circular Economy Package calls for further clarification of the definition of waste as well as for a better application of the waste hierarchy with emphasis being put on increasing both the quantity and the quality of recycling (Pouikli 2020). The key-aspects of this Circular Economy Package aim at demonstrating why the development of standards underpins future legislation. Such research tools of demonstration include primary developers or secondary researchers covering relevant policies, as this, out of the newly created CENCENELEC group, is responsible for drafting standards related to the material efficiency of products (Hughes 2017).

The ongoing generated EU Directives have to be briefly reviewed, enabling policymakers and plan designers to provide an indication of the likely requirements for industry of future EU and international legislation. The general requirements upon basic entrepreneurial, commercial, manufacturing, and industrial sectors, should be commented in alignment with suggestions for methods of compliance. In this respect, and taking into consideration that CE involves fundamental changes in production and consumption systems, a short-term research orientation can focus on the distinction between private and public law to underline the traditional private law regimes, in order to provide a sound basis to improve the law's capacity to foster the CE (Ballardini et al. 2021).

$\mathrm{CE}$ involves policies in holistically approaching the linkages between resource, substance, product and waste, in alignment with the interactions between waste, product, and chemical laws. In such context it is crucial for CE policymakers to consider the fact that waste, other than pollution, can be conceived of as a raw material of utility mainly in a production process (Pouikli 2020). The life-cycle thinking incorporated in the CE conceptualization is stressing out the need to consider:

(a) The environmental impacts of an entire material life-cycle in a holistic manner (Pouikli 2020). In such a context, the regulation of many types of energy-consuming products can be accomplished, providing that they meet generic or specific measures concerning their use of energy. The aim is to reduce their environmental impact, improve their energy efficiency, and cut greenhouse gas emissions (Beheshti 2020).

(b) The issue of protecting the rights of workers in the field of waste processing, regarding the creation of unified rules and standards, and as a result, the implementation of the developed norms in national legislation (Ilyassova et al. 2020).

Contemporary paths of environmental legislation are involving inter alia to acts of repairing, reusing and leasing, where selected private law fields are currently failing to provide the incentives needed for directing innovations and businesses toward more sustainable models. In the relevant literature its was denoted that this mainstream utility 
approach to property has become untenable in real world situations where the impact of both tangible and intellectual property law frameworks on ecological integrity should be prioritized (Ballardini et al. 2021). Intellectual property can be approached with the following four political dimensions derived from property law theories: (a) utility theory (or utilitarianism), (b) labor theory, (c) personality theory, and (d) social planning theory. For the scope of this study the most "impersonal-liking" theories, that of utility and social planning are mostly influential (Ballardini et al. 2021).

Therefore, there is imperative need of further investigating the shortcomings of the mainstream utility economic approach to the private law pillar of "property" in fostering socially desirable developments, such as sustainability, as the utmost priority determinant of the CE context. In this research framework two prominent private law regimes, namely intellectual property and property laws, showed that legal practices that reflect more social planning types of theory might better facilitate a gradual and swifter transition toward the CE. This switch is also challenging since:

- It enables a smoother linkage between private law regimes with the foundations of public areas of law, a way of harmonizing the two frameworks in achieving a sustainable CE among EU countries. However the adaptability effectiveness to other national or continental contexts remains as a research objective example for future analysis (Ballardini et al. 2021).

- Fostering CE and abiding to its environmental sustainability traits in private law requires taking a holistic, rather than a sectoral, approach. Environmental, economic and social aspects of sustainability are interlinked, thus a better understanding of environmental sustainability predominately requires the protection and preservation of the natural capital. From an economics point of view harnessing the creative forces of the market economy is a prerequisite toward the new and sustainable routes of production and consumption (Ballardini et al. 2021).

At the following Table 1 the key-aspects regarding the "policies" orientation of the existing EU legislative framework is presented as follows:

Table 1. Key-aspects and legislative tools regarding the "policies" dimension.

\begin{tabular}{|c|c|c|}
\hline Key-Aspects & Legislative Tools & Refs \\
\hline $\begin{array}{l}\text { Current EU policies for products; } \\
\text { Policy instrument for addressing resource } \\
\text { efficiency and affecting CE promotion; } \\
\text { Harmonization of ecodesign law across EU } \\
\text { States toward mandatory ecological } \\
\text { requirements: reparability or durability for } \\
\text { energy-related products sold within the EU }\end{array}$ & $\begin{array}{l}\text { Ecodesign Directive (Directive, 2009/125/EC) } \\
\text { Energy Labelling Regulation (Directive, 2017/1369) } \\
\text { Ecolabel Regulation (Directive 66/2010) } \\
\text { Green Public Procurement Directive (Directive, } \\
2014 / 24 / \text { EU) } \\
\text { Extended Producer Responsibility: Articles } 8 \text { and 8a in the } \\
\text { Waste Directive, as amended by Directive, 2018/851/EU }\end{array}$ & $\begin{array}{l}\text { (Ballardini et al. } \\
\text { 2021; Beheshti } \\
\text { 2020) }\end{array}$ \\
\hline $\begin{array}{l}\text { Repairability, refurbishability, reusability, and } \\
\text { shareability of products }\end{array}$ & $\begin{array}{l}\text { EU Green Deal Communication and the Circular Economy } \\
\text { Action Plan }\end{array}$ & $\begin{array}{l}\text { (Ballardini et al. } \\
\text { 2021) }\end{array}$ \\
\hline $\begin{array}{l}\text { Whole production cycle from the: (a) Use of } \\
\text { raw materials, design, production, distribution } \\
\text { and consumption of products and services; (b) } \\
\text { disposal and recycling of materials used as } \\
\text { secondary raw materials }\end{array}$ & $\begin{array}{l}\text { European Commission, Action Plan } 2015 \\
\text { European Commission, Implementation Report } 2019\end{array}$ & $\begin{array}{l}\text { (Mak and Terryn } \\
\text { 2020) }\end{array}$ \\
\hline $\begin{array}{l}\text { Environmental challenges regarding: (a) } \\
\text { Climate change; Air and water pollution, land } \\
\text { use and waste; (b) environmental protection, } \\
\text { better information in the fields of energy and } \\
\text { transportation }\end{array}$ & Consumer Policy Strategy 2007-2013 & $\begin{array}{l}\text { (Mak and Terryn } \\
\text { 2020) }\end{array}$ \\
\hline “Green” claims & $\begin{array}{l}\text { Unfair Commercial Practices Directive (UCPD) } \\
\text { Directive 2009/72/EC; Directive 2009/125/EC } \\
\text { Directive 2010/31/EU; Directive 2012/27/EU } \\
\text { Regulation 834/ 2007; Regulation (EC) No 1222/2009 }\end{array}$ & $\begin{array}{l}\text { (Mak and Terryn } \\
\text { 2020) }\end{array}$ \\
\hline
\end{tabular}


Based on Table 1, above, it is noteworthy that, among others, the current evolution of EU waste law and policy necessitates the utility of extended producer responsibility (hereinafter EPR), as widely applicable tool of environmental policy (Pouikli 2020). EPR sustains a two-fold target: internalization of environmental externalities related to end-oflife management and fostering the operational implementation of sustainable product and waste management schemes in alignment with the waste hierarchy and with qualitative recycling and recovery targets. Such an instrumental tool is shifting the responsibility upstream to the producer away from municipalities, while incentivising producers to incorporate environmental considerations in their products design (Pouikli 2020). Research target is entailing the investigation of opportunities to move toward a more effective EPR while adopting flexible policy instruments. Primarily, definition of EPR, and secondary its implementation schemes in EU law can be interpreted regarding the role of EPR to accomplish targets relating to waste management and product design requirements under the CE context and convergence between waste and product laws (Pouikli 2020).

An EPR system or scheme can be an individual system when a producer organizes its own system (individual producer responsibility, hereinafter IPR), or a collective system (collective producer responsibility, CPR) when several producers decide to collaborate and thus transfer their responsibility to a specific organization: a producer responsibility organization (hereinafter PRO). A producer responsibility organization is setting up in collective EPR schemes in order to put into effect the EPR principle in the name of adhering companies through financing the collection and treatment of targeted waste, organizing and supervising these activities and managing the corresponding data. Typical examples in EU members are that of Duales System Deutschland in Germany and Eco-Emballages in France (Pouikli 2020). However, it can be denoted that in general the relatively sparse literature that has engaged with the relationship between consumer law and sustainability reveals that EU policy has primarily focused on "light touch" regimes that appeal to EU citizens to endorse sustainable lifestyles (Mak and Terryn 2020).

Private individuals and organizations operating in the market, are key-determinants to complement public regulations in areas of private law like IPR and property laws impacting on repair, reuse, and share (such as leasing) of goods. In this respect, radical changes need to occur in the way of conceiving the property entity, such as in IP and property law frameworks in order for these regimes to envisage the CE concept (Ballardini et al. 2021). Moreover, EPR schemes will promote the separate collection of waste, in meeting the municipal waste and packaging recycling targets, and through the avoidance of separately collected waste being sent to landfill and encouraging producers to create more sustainable products. EPR may be also a key instrument in promoting re-use, waste prevention, and eco-design as well as industrial symbiosis by ensuring the provision of high-quality secondary raw materials. Besides, EU States are encouraged via their EPR schemes to modulate fees for such schemes on the basis of durability, reparability, reusability, and the presence of hazardous substances, and a database will be created containing information on hazardous substances in products, thus significantly focusing more on qualitative prevention adopting substance restriction or bans on substances or materials that can cause negative environmental impacts when recovered, recycled, or disposed (Pouikli 2020; Ilyassova et al. 2020). In this respect the adoption of the term "durable lifecycle" refers to making goods of better design to become efficient and simple, ultimately leading to the extension of product life, thus, commercial buyer engaged in such a CE business model has therefore particular interests of obtaining such "durable lifecycled" goods (Beheshti 2020).

\subsection{Legislative Tools toward Circular Economy-The "Products" Dimension}

The "products" dimension should play a decisive role in drawing legislative tools and regulations toward a CE-market. Next to this social capital point of view, from a natural capital (ecology) point of view, research studies have focused on the possibility of water management that, as a vital public tool for better understanding the water market, appreci- 
ating and protecting the natural wealth. The role of water is predominately important for human survival of all, present and future, generations. In this sense, states have played a determining role that transcends territorial boundaries, requiring that international agreements be established for uniform mechanisms of accreditation of promoted practices, fines, and benefits adhering to the movement of CE (Da Rosa and Ramos 2018). Therefore, while inhibiting and encouraging the behavior of state, private, and corporate agents, it is vital, first the suitable design of culturally acceptable mechanisms of sanctions and benefits offered (Da Rosa and Ramos 2018) and, second, products design their relationship with the legislative framework governing parties' rights and duties in the context of the sale of goods transactions (Beheshti 2020). Toward the environmental considerations of social planning it is indicatively noted:

(a) The imperative urgency of waste management law since, in the past, during these key political events, there was no reliable scientific data on the risks associated with e-waste, and the corresponding technical capacity necessary to work with data in the context of rapidly growing rates of e-waste production was not used (Ilyassova et al. 2020).

(b) In a buyer's decision to communicate its particular purpose of using goods compliant with CE, once the buyer's purpose of using goods in the circular business model is known to the seller, a measure of responsibility automatically shifts to the latter such that, where necessary and appropriate, it should investigate the buyer's needs. As such, it is unacceptable that the seller may seek to eschew its obligation by showing that it has received inadequate information from the buyer. Based on recent judicial decisions reported in literature (Beheshti 2020), the buyer should ensure that his/her full intention to use goods for a particular purpose is properly conveyed to the seller. However, a critique of the buyer must explicitly communicate explicitly its particular purpose to enhance the seller's knowledge so that the buyer can safely rely on the seller's skill and judgment, it is treated with skeptism, since this argumentation may appear restrictive and commercially unrealistic (Beheshti 2020).

In Table 2 the key-aspects regarding the "products" orientation of the existing EU legislative framework are presented as follows:

Based on Table 2, it is noteworthy that the aforesaid key-aspects have been characterized of utmost importance for the CE. As such, this regulatory framework can promote the transition from a linear (involving take-make-dispose)- to a circular- economy, thus, directives and regulations should promote such activities (Pouikli 2020). In this context, the main piece of EU legislation is epitomized to the repair and reuse, while new business models can be based on sharing and renting. Nevertheless, it is noteworthy that while earlier issued legislative tools have been well established and effectively adapted to national or international environmental situations, the most recent legislative tool of promoting law in force, especially that of the new Circular Economy Action Plan, it is still underdeveloped in an socio-environmental context (Ballardini et al. 2021). It is indicatively noted that according to the Circular Economy Action Plan only around $40 \%$ of the waste generated by EU households is currently recycled whereas, in 2013, the total waste generation in the EU amounted to approximately 2.5 billion tons of which 1.6 billion tons were not used or recycled (Pouikli 2020). 
Table 2. Key-aspects and legislative tools regarding the "products" dimension.

\begin{tabular}{lll}
\hline \multicolumn{1}{c}{ Key-Aspects } & \multicolumn{1}{c}{ Legislative Tools } & Refs \\
\hline $\begin{array}{l}\text { Repairability, refurbishability, reusability, } \\
\begin{array}{l}\text { as well as shareability (also including } \\
\text { leasing) of products }\end{array}\end{array}$ & $\begin{array}{l}\text { Waste Framework } \\
\text { (Directive 2008/98/EC) }\end{array}$ & (Ballardini et al. \\
\hline $\begin{array}{l}\text { Re-manufacturing, refurbishing, } \\
\text { repairing, and re-using toward reduction } \\
\begin{array}{l}\text { of the quantities of new material needed } \\
\text { in national economies }\end{array}\end{array}$ & $\begin{array}{l}\text { International Resource Panel of the United Nations Environment } \\
\text { Programme }\end{array}$ & (Ballardini et al. \\
\hline
\end{tabular}

in national economies

Waste hierarchy, emphasizing on increasing both the quantity and the quality of recycling; product take-back requirements; economic and market-based instruments; regulations and performance standards; information-based instruments (a) Circular Economy Package; (b) EPR, as a significant financial and operational instrument which fosters the requirements of the Circular Economy Package in the fields of EU waste law and policy, linking relevant legislative and policy issues; (c) Directive 94/62/EC on packaging and packaging waste; (d) Directive 2000/53/EC on end-of-life vehicles; (e) Directive 2012/19/EC on waste electrical and electronic equipment (WEEE); (f) Directive 2006/66 on batteries and accumulators; (g) The amended Waste Framework Directive 2018/851 concerning the strategic importance of waste prevention by confirming its top priority for waste legislation/waste hierarchy

Electronic products and sustainable development

The United Nations Environment Programme (UNEP)
(Ilyassova et al. 2020)

\subsection{Legislative Tools towards Circular Economy-The "Services" Dimension}

The legislative production regarding the "services" dimension it is mainly focused on the organization fields of quality management and waste management. In this respect, the environmental dimension of CE should be considered as a key aspect as part of a broader policy mix aimed at stimulating sustainable production on the supply side of the market, and sustainable consumption on the demand side. Consequently, consumers can be considered as active contributors to $\mathrm{CE}$ citizens contributing to $\mathrm{CE}$ through their actions on the demand side, and EU law has sought to facilitate environmentally friendly consumer choices through information rights (Mak and Terryn 2020). Therefore, consumers may be stimulated to opt for repair or to engage in shared use of products through "servitization," thus, envisaging sustainability when shaping consumer law in the light of such a measurable context (Mak and Terryn 2020).

From a technology point of view, it is particularly interesting the investigation of how circular economics are capable to address and use smart technology, while considering the lack of consideration given to ownership issues in such socio-economic contexts (Thomas 2018). The extent to which CE requires controlling goods down-stream, it has been approached by analyzing the implications of smart technology (Thomas 2018). This leads to a close comparison of claimed benefits between companies, arising from CE approaches to smart technology with the potential costs of development, control (or lacking behind) of novel technologies (Thomas 2018). In Table 3 the key aspects regarding the "services" orientation of the existing EU legislative framework are presented as follows:

Based on Table 3, it is noteworthy that among the aforementioned key aspects a legal issue of high social interest toward "services" dimension of the CE, it is the development of a contractual framework for the sale of goods in order to investigate whether the national sales law regime can promote a circular business model (Beheshti 2020). The main constraint of such a contractual framework development is the absence of rules and regulations requiring manufacturers produce goods compliant with the CE, implying that, in the case of UK, English Sale of Goods Act has limited capacity to hold manufacturers accountable, but vulnerable to manufacture goods compliant with the CE (Beheshti 2020). Therefore, in investigating the terms abided to national sales law from the CE prospect, buyers should 
ensure that their particular intention of obtaining goods compliant with the CE is fully communicated to the manufacturers (Beheshti 2020). Another critical issue of legal interest at the "service" dimension is the examination of those creation mechanisms, through the legal system, which can induce the appropriate behavior to the effectiveness and expansion of the premises of the CE. Considering the microeconomics assumption that agents are optimizing subjects, it is challenging the normative creation of fines and benefits toward the adoption of a pattern of behavior related to the CE (Da Rosa and Ramos 2018). From a generalized individualism-consumerism point of view it should be prioritized the creation of homologating bodies of sustainable practices by corporations, with the accreditation of these behaviors of eco-consumption, industrial ecology, economic functionality, and reuse (Da Rosa and Ramos 2018).

Table 3. Key-aspects and legislative tools regarding the "services" dimension.

\begin{tabular}{llc}
\hline \multicolumn{1}{c}{ Key-Aspects } & \multicolumn{1}{c}{ Legislative Tools } & \multicolumn{1}{c}{ Refs } \\
\hline $\begin{array}{l}\text { Waste management among involved stakeholders } \\
\text { Supporting decision-making of producers }\end{array}$ & $\begin{array}{l}\text { Polluter Pays Principle (PPP), as a } \\
\text { managerial tool to regulate the division } \\
\text { of responsibilities among waste } \\
\text { managing stakeholders and } \\
\text { decision-making producers }\end{array}$ & (Pouikli 2020) \\
\hline $\begin{array}{l}\text { Legislation on consumer sales } \\
\text { Legislation on product liability and product safety }\end{array}$ & $\begin{array}{l}\text { Consumer Sales Directive 1999 and 2019 } \\
\text { General Product Safety Directive 2001/95 }\end{array}$ & (Mak and \\
\hline $\begin{array}{l}\text { Terryn 2020) } \\
\text { e-waste management }\end{array}$ & $\begin{array}{l}\text { 8 and 12 United Nations Sustainable } \\
\text { Development Goals (SDGs) }\end{array}$ & (Ilyassova et al. \\
\hline
\end{tabular}

\footnotetext{
(a) Quality terms incurring in national (UK) sales law whereby the buyer may hold the manufacturer responsible for designing and producing goods. This assumption is that such a purpose is well known to the seller through public law quality standards; (b) the legislation of "Ecodesign for Energy Related Products Regulations Ecodesign for Energy Related Products Regulations 2010

\section{Research Considerations of Legal Practices and Social Planning towards the Circular Economy}

The existing legal theories enacted in EU, especially among the Western developed economies, are justifying private property and they are based on some form of utilitarian property theory that emphasizes on rather straightforward economic efficiency. Contrarily, environmental sustainability has not always counted for which, in turn, is leading to a ripple effect (Ballardini et al. 2021).

Environmental sustainability is not the major objective in private law, thus, it is insufficiently reflected in existing theories and practices (Ballardini et al. 2021). However, private law plays a decisive role in fostering technological innovation and creativity, as well as in regulating businesses' processes. Therefore, the need for the assessment of private laws' ability to fulfil the criteria of CE applicability is imperative. Market, or mixed, economy, is implying the urgency of transition to CE in order to steer sustainability principles, to develop technological innovations and to support viable business models. In the EU market, EU-State contributors of mixed economy can form only regulations and issue laws for companies and consumers, having no direct control or intervention on what products and services should be produced and consumed. These States are also unlikely to know the functionality complexities about production and consumption systems, thus, entailing how operation changes should order and embed $C E$ types of vision in market economy (Ballardini et al. 2021). Under the CE concept, EPR is actually valued as a dynamic and evolving policy that needs to be continually reassessed in order to incorporate new 
incentive mechanisms for industries to permanently improve their products and processes (Pouikli 2020).

Environmental sustainability does not necessarily exclude economic growth, since green growth uses natural capital in sustainable ways. Consequently, the key aspects of private law are the following: persons, property, contract, tort liability, and remedies. These key-aspects should be embedded into private law in engaging sustainability values, not just that of sectorial inclusion into individual private law regimes (Ballardini et al. 2021). Such an implementation concerns both product and waste policy spheres, in order to close the loops between waste management operations and product-oriented environmental policies. In such a way it should be ensured fair competition between EPR schemes on the national and the EU contexts, thus improving the transparency of performance and costs/fees. Emphasis is given on preventing free-riding by producers and compliance with PROs with respect to managerial responsibilities and environmental conformity with internal market regulations (Pouikli 2020).

Besides, assuming that the terms of "environmental sustainability" and "CE" contain the same theoretical weight and practical functionality in the law system, fostering CE, or "environmental sustainability" in general, it should be the mainstream priority among EU States. The issuing of such directives and regulation can be envisaged as just and attractive in alignment with social planning and property justification. In such a way, a change in the ways of justifying and conceiving private property, might be valued as an important necessity (Ballardini et al. 2021). Consequently, there is possibility to involve consumers in the pursuit of a CE project, thus fostering sustainable consumption. In order to achieve these goals, policymaking in European consumer law has to revisit the linkage between environmental goals and consumer protection. Consumer policy and environmental policy can no longer be considered as separate policies (Mak and Terryn 2020).

According to the new Circular Economy Action Plan, the EC will introduce sustainable legislative initiatives, being initiated by sustainable policies of production in the future. The objective of the aforesaid CE Economy Action Plan is to broaden the range of products covered by the eco-design framework and make it deliver on circularity (Ballardini et al. 2021). Based on the Directives of Waste Framework and the EcoDesign it can be stated that public law regimes are important and relevant, but they should be proven insufficient. It is noteworthy that designing requirements for repairability of all trading products and household appliances within the framework of the EcoDesign Directive would require decades of work by administrative bodies, and still the ultimate conformation result would not be surely satisfactory. Moreover, public law situations could become ineffective, or even blocked, by private law regimes if the goals between the two areas, private-public, are not aligned to each other (Ballardini et al. 2021).

Regarding the public law regimes, the intrinsic nature of public law acknowledges the crucial role of repairability, refurbishability, reusability, and shareability (including leasing) of products to achieve $\mathrm{CE}$, yet, being short-sighted envisage perspectives in a market economy. Similar conclusions can be made by national public policy measures, where EU States are inclined to go far beyond the European policies in their national strategies, though they are incomplete per se, e.g., the powerful tool, value added tax (VAT) rates, is partly controlled from the EU States which can easily promote certain business models, e.g., repair services, by lowering the VAT (Ballardini et al. 2021).

In order to support the public law, the EPR policy sought to shift from local authorities and taxpayers (i.e., the public budget) to producers the burden of taking responsibility to collect end-of-life products and to sort them before their final treatment (Pouikli 2020). According to Article 4 of the Waste Framework Directive, in which the different options for managing waste from "best" to "worst" are listed from an environmental perspective, the priority order is as follows: prevention, (preparing for) re-use, recycling, recovery and, as the least preferred option, disposal; which contains landfilling and incineration without energy recovery (Pouikli 2020). This waste hierarchy is not considered as a rigid prescription, since different methods of waste treatment involve different environmental 
impacts (Pouikli 2020). In such an analysis, EPR constitutes a typical second-best policy approach, whose importance lies in the attempt to correct market failures or imperfections deriving from the breach of the most basic rule of waste law-that is of prohibition of the abandonment and dumping wastes of uncontrolled management. The economic background of implementing sound EPR schemes urges producers to internalize treatment and disposal costs so that they have an incentive to design products that last longer and are more easily treated after use (Pouikli 2020).

Another critique over private law regimes resides in the fact of ignoring environmental sustainability in private law because of heavy reliance of private law regimes on pure economic efficiency, utility, and incentives, with the main focus on individual rights ownership (Ballardini et al. 2021). Consumers' shared responsibility for environmental protection toward the transition to a services-based circular industry seems problematic. Consumers are certainly exposed to numerous risks while entering into services agreements. Besides, regarding CE implementation, there is little scope for consumer responsibility beyond taking an informed choice for sustainable product-service bundles. The work of legislators lies in making such an informed choice to ensure the protection of consumers in the product-service system (PSS) either through hard law, or at least to ensure that consumer interests are sufficiently and structurally taken into account when setting standards for services (Mak and Terryn 2020).

Another noteworthy consideration of social planning and legislative interest toward $\mathrm{CE}$ is the fact that in countries where a waste management system is lacking or not fully developed yet, e-waste is typically disposed of, incinerated, sold or recycled by utilizing low-quality technologies (Ilyassova et al. 2020). In countries with targeted policies and legislation on e-waste and with developed infrastructure, e-waste that is not recorded as collected and processed by official recycling systems is often disposed with ordinary household waste. E-waste is of pronounced importance since the EU legislation production has been traditionally focused on environmental issues, where only $35 \%$ of e-waste ends up in official records of waste collection and recycling systems (Ilyassova et al. 2020). Such a limited research is also attributed to dynamic changes in national or international laws, necessitating a pluralism of approaching the concurring environmental-legislative issues, as well as reviewing trends and prospects regarding international regulations among different types of wastes' co-disposed, including that of electronic, industrial, manufacturing, hospital, and domestic (Ilyassova et al. 2020).

\section{Discussion}

A critical consideration of legislative interest is the evaluation of environmental hazards associated with the REE industry and the EU's existing environmental and radiation protection. To this end legislation and best practice documentation should be anticipated and a comparison of key regulative aspects among selected countries with existing REE mining industries can be deployed (Keith-Roach et al. 2015).

However, the aforementioned best practice documentation can be considered in alignment with the companies' size and the time span of implementation. Indeed, while the applicable processes can be proven appropriate for all business types, the time span required for realization varies significantly. In particular, large companies tend to suffer from bureaucratic structures, whereas small and micro sized companies are commonly lacking knowledge and resources available (Miehe et al. 2015). In practice, the aforementioned lengthy and complex legislative constraints could be treated by the development of database architectures, which can take into consideration the minimal technical requirements, access and display of records, as well as searching and administrating facilities offered (Macovescu and Guta 2012).

Actually, the foundation of relevant industry-centered legislation for, first, industrial health and safety and, second, environmental orientation, should be convergent with the ongoing technological progress, workforce protection, and local societies' acceptability. To this end shortcomings in legislation should be treated in a proactive way, being un- 
dertaken by specialized operating companies to support a multi-parametric background about: theory of law, environmental protection-remediation and technological expertise. Indeed, the balance between a minimum acceptable level of protecting intellectual property should respond about how much protection is needed, being linked to R\&D costs incurred in order to pursue innovation through creativity (Ballardini et al. 2021).

\section{Conclusions}

In better approaching the ways under which the legislative tools should serve the environmental protection, it is noteworthy the collective responsibility of producers, consumers, and central governments toward the environmental impacts of products, throughout their life cycle, including end-of-life management. Therefore, it is proven that the regulation of sharing responsibilities for waste management and pursuing sustainability goals in the $\mathrm{CE}$ projects is of utmost importance. The main legislative constraints of such CE development are the lack of harmonized definitions and operabilityconflicting interests among counterparts, access to transparent information, adequacy of controlling and monitoring mechanisms, determination of incurring costs to be internalized through recycling procedures, as well as improvement of eco-design and circular design promotion, especially in the field of packaging waste, but not mixed collection, among EU States to motivate producers to turn to eco- and circular design. Actually, the roles of eco-design and cleaner production are supplementary, but not exclusive, to resolve the underlying critical issue of the linear material consumption and waste generation associated with the use of disposable products of wide consumerism.

Critical considerations for future research must concentrate on finding solutions to facilitate the implementation of CE principles for these CE-made products, while supporting the development of new circular business models. Besides, future research should ensure the engagement of consumers, being appreciated as environmentally alarmed citizens with a shared responsibility toward $\mathrm{CE}$, even though their practical impact is limited, partly due to problems of enforcement. It cannot be signified that, although consumers are generally willing to adapt their behavior towards green choices, EU consumer law is of limited success in facilitating, or even stimulating, such choices.

Actually, the contradictions between public-private law systems and that of formerrecent law regimes, are indicative cases of generating possible clashes that may be resolved when CE conceptualization is broadly "diffused" to local societies and the law regimes have a role to play either at a proactive or as post-treatment tools of legal practices and social planning of CE. Finally, among such legal practices and social planning of CE, it cannot be undermined the contribution of eco-efficiency, which is reflecting the necessary transition from a linear to a $\mathrm{CE}$, in terms of resources utility through carbon abatement mechanisms and emissions control.

Funding: This research received no external funding.

Institutional Review Board Statement: No humans or animals are involved in the study/research.

Informed Consent Statement: Not applicable.

Data Availability Statement: Not applicable.

Conflicts of Interest: The author declares no conflict of interest.

\section{References}

Adeyemo, Omobolanle, and John Smallwood. 2017. Impact of Occupational Health and Safety Legislation on Performance Improvement in the Nigerian Construction Industry. Procedia Engineering 196: 785-91. [CrossRef]

Adeyemo, Omobolanle, and John Smallwood. 2019. Barriers to the implementation of occupational health and safety legislation in the Nigerian construction industry. Paper presented at the 22nd International Conference on Advancement of Construction Management and Real Estate, CRIOCM 2017, Melbourne, Australia, November 20-23; pp. 1163-70.

Arocena, Pablo, and Imanol Nunez. 2009. The effect of occupational safety legislation in preventing accidents at work: Traditional versus advanced manufacturing industries. Environment and Planning C: Government and Policy 27: 159-74. [CrossRef] 
Ballardini, Rosa Maria, Janne Kaisto, and Jukka Similä. 2021. Developing novel property concepts in private law to foster the circular economy. Journal of Cleaner Production 279: 123747. [CrossRef]

Beheshti, Reza. 2020. The circular economy and the implied terms of contract in English sales law. Journal of Property, Planning and Environmental Law. [CrossRef]

Chaudron, Camille, Melanie Faucher, Laurent Bazinet, and Manuele Margni. 2019. The cost is not enough-An alternative eco-efficiency approach applied to cranberry de-acidification. Journal of Cleaner Production 232: 391-99. [CrossRef]

Cooper, Peter. 1992. Overview of the effect of environmental legislation on the UK textile wet processing industry. Journal of the Society of Dyers and Colourists 108: 176-82. [CrossRef]

Da Rosa, Alexandre Morais, and Ana Luisa Schmidt Ramos. 2018. Circular economy, human behavior and law. WIT Transactions on the Built Environment 179: 35-44. [CrossRef]

Dodd, Kevin James. 2002. Health and safety legislation: Issues for the synthetic dyestuff industry in the UK. Review of Progress in Coloration and Related Topics 32: 103-17. [CrossRef]

Hogan, William Thomas. 1995. Environmental legislation and the U.S. steel industry. Iron and Steel Engineer 72: 40-42.

Hughes, Richard. 2017. The EU Circular Economy Package—Life Cycle Thinking to Life Cycle Law? Procedia CIRP 61: 10-16. [CrossRef]

Ilyassova, Gulzhazira, Aigul Nukusheva, Leila Arenova, Guldana Karzhassova, and Marzhangul Akimzhanova. 2020. Prospects of legal regulation in the field of electronic waste management in the context of a circular economy. International Environmental Agreements: Politics, Law and Economics. [CrossRef]

Keith-Roach, Miranda, Bertil Grundfelt, Lars Olof Höglund, Anne Kousa, Esa Pohjolainen, Paloma Magistrati, Vassiliki Aggelatou, Nicolo Olivieri, and Andrea Ferrari. 2015. Environmental Legislation and Best Practice in the Emerging European Rare Earth Element Industry. In Rare Earths Industry: Technological, Economic, and Environmental Implications. Amsterdam: Elsevier, pp. 279-91. [CrossRef]

Lu, Shixin, and Ning Xia. 2004. Meeting the challenge-Compliance with environmental legislation on offshore oil industry in China. Paper presented at the SPE International Conference on Health, Safety and Environment in Oil and Gas Exploration and Production, Calgary, AB, Canada, March 29-31.

Macovescu, Gabriela, and Sergiu Adrian Guta. 2012. Environmental legislation database for the leather and footwear industry. Leather and Footwear Journal 12: 19-26.

Mak, Vanessa, and Evelyne Terryn. 2020. Circular Economy and Consumer Protection: The Consumer as a Citizen and the Limits of Empowerment Through Consumer Law. Journal of Consumer Policy 43: 227-48. [CrossRef]

Mendoza, Joan Manuel F., Francesco D’Aponte, Diego Gualtieri, and Adisa Azapagic. 2019. Disposable baby diapers: Life cycle costs, eco-efficiency and circular economy. Journal of Cleaner Production 211: 455-67. [CrossRef]

Miehe, Robert, Sebastian Mueller, Ralf Schneider, Sylvia Wahren, and Markus Hornberger. 2015. Integrated hazardous materials management: Combining requirements from various environmental legislations to enable effective business compliance processes in industries. International Journal of Precision Engineering and Manufacturing—Green Technology 2: 289-98. [CrossRef]

Philippot, Maeva, Garbine Alvarez, Elixabete Ayerbe, Joeri Van Mierlo, and Maarten Messagie. 2019. Eco-efficiency of a lithium-ion battery for electric vehicles: Influence of manufacturing country and commodity prices on ghg emissions and costs. Batteries 5: 23. [CrossRef]

Pouikli, Kleoniki. 2020. Concretising the role of extended producer responsibility in European Union waste law and policy through the lens of the circular economy. ERA Forum 20: 491-508. [CrossRef]

Simpson, J. A., J. Binkley, and P. H. McMahon. 2000. New environmental legislation affecting textile-industry manufacturing. Journal of the Textile Institute 91: 65-72. [CrossRef]

Thomas, Sean. 2018. Law, smart technology, and circular economy: All watched over by machines of loving grace? Law, Innovation and Technology 10: 230-65. [CrossRef]

Tovar, Beartiz, and Miluse Tichavska. 2019. Environmental cost and eco-efficiency from vessel emissions under diverse SOx regulatory frameworks: A special focus on passenger port hubs. Transportation Research Part D: Transport and Environment 69: 1-12. [CrossRef]

ul Haq, Shamsheer, Ismet Boz, Pomi Shahbaz, and Cagatay Yıldırım. 2020. Evaluating eco-efficiency and optimal levels of fertilizer use based on the social cost and social benefits in tea production. Environmental Science and Pollution Research 27: 33008-19. [CrossRef]

Valente, Antonio, Diego Iribarren, Jose-Luis Gálvez-Martos, and Javier Dufour. 2019. Robust eco-efficiency assessment of hydrogen from biomass gasification as an alternative to conventional hydrogen: A life-cycle study with and without external costs. Science of the Total Environment 650: 1465-75. [CrossRef] [PubMed] 